\title{
O Curso de História na Universidade Federal de Alagoas: dos Primórdios à sua Consolidação (1952-1979)
}

Ana Luiza Araújo Porto*

Universidade Estadual de Alagoas

\begin{abstract}
Resumo
O propósito fundamental deste texto concentra-se na História da Formação do Profissional de História na Universidade Federal de Alagoas, das origens do curso até a década de 1970, quando ele se consolida. Constitui uma pesquisa em História da Educação que busca acompanhar a constituição do primeiro curso universitário de História em Alagoas, no contexto de fundação da Faculdade de Filosofia, na década de 50 do século XX que, na época era um curso de História e Geografia. Além de levantamento bibliográfico e da documentação institucional a ser compulsada, foram fontes deste estudo também as entrevistas com exprofessores e professores atuantes que foram alunos do curso.
\end{abstract}

Palavras-chave: História do Ensino Superior em Alagoas - o curso de História na UFAL.

\begin{abstract}
The main purpose of this text focuses on the history of the Vocational Training of History at the Federal University of Alagoas, the origins of the course until the 1970s, when it is consolidated. It is a search in History of Education that seeks to monitor the formation of the first university course of history in Alagoas, in the context of the foundation of the Philosophy Faculty, in the 50 s of the twentieth century that at the time was a course in History and Geography. In addition to bibliographic and institutional documentation to be compulsive, sources in this study were also interviews with former teachers and teachers who were active students of the course.
\end{abstract}

Keywords: History of Higher Education in Alagoas - the course of history in UFAL.

É inegável que a década de (19)50 é um marco para Alagoas que, mesmo não abandonando seu caráter conservador, se moderniza no sentido de adquirir outros hábitos, que demandam outros tipos de serviços, especialmente no campo da educação escolar, sobretudo influenciados pelos bens de consumo que começam a chegar e pela complexificação por que vai passar a máquina do Estado. Assim, pois, mesmo vivenciando uma modernização conservadora, a diversificação das atividades produtivas e a ampliação dos serviços, sobretudo na esfera pública, dentro do estado de Alagoas, acabaram por exigir mais formação escolarizada, o que levou à expansão da rede secundária de ensino, que terminou por ser beneficiada em seu processo de expansão pela Campanha Nacional de Educandários Gratuitos. Essa expansão da rede secundária de ensino, na década de 1950, criou importantes entidades educacionais em Alagoas. É nesse contexto que se faz candente a fundação de uma Faculdade para formar professores secundários. A Faculdade de Filosofia foi a solução encontrada. Entidade

\footnotetext{
*É Mestra em Educação Brasileira pelo PPGE/ CEDU/ UFAL. É professora do Programa Especial de Graduação de Professores da Universidade Estadual de Alagoas. Este trabalho é parte da dissertação de mestrado cuja pesquisa foi financiada pela FAPEAL.
} 
privada fundada em 1950, sob a liderança de um expressivo educador católico à época, o padre Teófanes Augusto de Araújo Barros. Ela iniciou seu pleno funcionamento em 1952, dando início às primeiras turmas, com os cursos superiores de bacharelado em Filosofia, História e Geografia, Letras Clássicas, Letras Neolatinas e Letras Anglo-Germânicas.

Em se tratando do curso de História e Geografia, que é o objeto do presente estudo, embora a USP tenha sido, segundo afirma Joana Neves, o modelo para os outros cursos posteriormente fundados no Brasil, o de História e Geografia da Faculdade de Filosofia de Alagoas - que é o mesmo que hoje integra a UFAL - foi buscar como modelo - como os demais cursos da FAFI, inclusive copiando seus currículos - o curso de História e Geografia da Faculdade Nacional de Filosofia, à época pertencente à Universidade do Brasil e que hoje faz parte da Universidade Federal do Rio de Janeiro, segundo nos informa Maria de Lourdes Fávero (1989). A busca da Faculdade Nacional de Filosofia como modelo para a criação da nossa faculdade, a se considerar o ethos da sociedade alagoana, bem como a conjuntura em que se deu o fato, é facilmente explicável: se a instituição nascia para formar profissionais para 0 magistério, nada melhor do que uma concepção napoleônica de educação superior que se voltava integralmente para o ensino profissionalizante, diferentemente da USP, que tinha como modelo a ser alcançado a universidade humboldtiana, que priorizava a pesquisa, ainda que se ocupasse da formação profissional.

A ligação umbilical ao Instituto Histórico também é um indício forte do quanto a marca do curso era tratar com um saber que se devia buscar somente nos livros e se apresentava como algo fechado e pronto e que não carecia de reelaboração e, muito menos, de questionamento, o que vem a diferir profundamente da historiografia contemporânea, que percebe o saber histórico como algo que necessita de constante reelaboração, à medida que novas fontes são descobertas e outros problemas vêm à tona em função dos mesmos objetos. Assim, o curso de História da FAFI - hoje no seio da Universidade Federal de Alagoas - é criado, na década de 1950, fortemente vinculado a um padrão de conhecimento assumido pela camada senhorial das Alagoas e que é oriundo do Instituto Histórico e Geográfico do Estado. 
O curso de História é fundado em Alagoas, junto com o curso de Geografia, fazendo parte de uma única formação curricular. Já a formação do quadro docente inicial será basicamente composta por bacharéis em Medicina, Direito e Engenharia, segundo nos afirmam os estudos de doutoramento do professor Elcio de Gusmão Verçosa (1996). Todos os fundadores do curso de História eram sócios do Instituto Histórico, segundo informam os arquivos relativos aos sócios do IHGAL, o que corrobora a idéia de que o curso nasce mantendo uma relação umbilical ao IHGAL, ligação essa que não se perdeu com o tempo. Pensando a graduação em História - como, de resto, os demais cursos que se estruturavam em bacharelado e licenciatura - além de percebermos que todos os cursos da Faculdade de Filosofia de Alagoas nascem e se desenvolvem com um objetivo bem definido, a saber, formar quadros para o magistério secundário e para atuar na máquina estatal, o que se configura como mais marcante na fundação desse curso é o caráter de autodidatismo dos seus docentes, os quais, sequer conheciam, por formação, o saber docente. Percebe-se claramente nesta geração - que eu chamo de geração de fundadores - não haver corpo docente habilitado para lecionar em cursos de formação de professores. O curso de História e Geografia criado pela FAFI tinha duração inicial de três anos, configurando-se como um bacharelado, com a habilitação pedagógica sendo feita na seção de Didática do curso de Pedagogia que foi fundado em 1955, em um ano de estudos pelos quais se outorgava outro diploma, neste caso, de licenciatura. Era o famoso modelo $3+1$, que legalmente vigorou até recentemente.

Quanto à composição da matriz curricular do curso na sua primeira versão, as disciplinas assim se apresentavam: Geografia Física, Geografia Humana, História da Antiguidade e Idade Média, Antropologia, Geografia do Brasil, História Contemporânea, História do Brasil, História das Américas, Etnografia do Brasil, Etnologia e História Moderna.

Pudemos perceber que não havia nesta matriz curricular da geração dos fundadores nenhuma disciplina que pensasse o saber histórico como algo que se constrói e que precisa de constante revisão, à medida que novas fontes são descobertas e que novos problemas são colocados pelos novos historiadores. Vale sublinhar que, pela matriz curricular adotada, o que contava, de fato, na formação de um professor não era o diálogo entre os saberes pedagógicos e 
os saberes de conteúdo, mas sim o conteúdo a ser ensinado na escola como eixo norteador do ensino. Pensar a didática não era questionar a relação conteúdo/forma, ou seja, questionar o estatuto do saber científico e refletir sobre a produção do conhecimento histórico, mas apenas criar novas maneiras de reproduzir um velho saber sobre o qual não faziam sentido questionamento, crítica, reformulação.

Pelas atas das reuniões da congregação da FAFI, depreende-se que 0 ambiente acadêmico dos primeiros anos resumia-se a aulas expositivas elaboradas pelos professores. Cotidianamente, quando muito, havia palestras proferidas pelos próprios professores do curso sobre temas cristalizados pela historiografia reinante no Instituto Histórico e já esboçada no primeiro capítulo deste texto e sobre aspectos da cultura alagoana, esta trazida à baila, insistentemente, por ninguém mais do que o Doutor Théo.

Em se tratando da pesquisa histórica, ela acontecia restrita ao Instituto Histórico e, de um modo bem particular, não se instituindo como atividade da Faculdade ou do curso. Assim, quando feita, mesmo que fora da FAFI, a pesquisa passava longe da ação docente e isso pode ser comprovado pela leitura dos diversos relatórios anuais que a faculdade estava obrigada a fazer, prestando contas de seu funcionamento ao MEC.

Quando da fundação da Universidade Federal de Alagoas em 1961 a FAFI foi incorporada e o curso de História de que tratamos até aqui foi incorporado também, à época já havia se separado do curso de Geografia. Quando da primeira reforma universitária a formação específica ficou, num primeiro momento, no Instituto de Filosofia e Ciências Humanas, que funcionava na Faculdade de Direito, na Praça do Montepio dos Artistas, no Centro da cidade, e depois, por um tempo, no Campus Tamandaré, no Pontal da Barra, estando, nesse período, junto com a Faculdade de Educação/ Departamento de Educação, quando estes também funcionavam no Campus Tamandaré, voltando a se separarem na segunda reforma, inclusive até fisicamente, com a saída deste último espaço físico, indo o curso de História, dentro de seu respectivo departamento, para o Centro de Ciências Humanas, Letras e Artes - CHLA, e o Departamento de Educação, para o Centro de Ciências Sociais Aplicadas - CCSA. 
Pelos parcos documentos disponíveis e por mim consultados para a realização deste trabalho, não foi possível precisar exatamente em que ano a separação entre Geografia e História aconteceu. Essa separação, no caso da História, trouxe benefícios, a partir do momento em que, no mínimo, deixou mais espaço para o estudo de saberes específicos.

De qualquer modo, os anos de 1960 para o curso de História são de difícil precisão e estudo, sobretudo por não haver nenhum material escrito acessível para ser consultado. Pode-se deduzir, pelas afirmativas feitas por Verçosa, que diz que não houve nenhuma ruptura de paradigma nesta década acerca da universidade, que poucas alterações aconteceram também no curso, sobretudo pela forma refratária às mudanças como agiam os religiosos católicos que foram a marca do curso e da Faculdade de Filosofia desde a fundação, bem como os docentes leigos que representavam a expressão do saber dominante.

Dando um salto cronológico, que é problemático, quando se pensa na lacuna deixada, mas que é plenamente justificável quando se tem em mente que a História é feita de fragmentos reunidos acerca de um passado que se deixou conhecer, dos anos da fundação do curso para a década de 1970 percebe-se, claramente, um panorama diferenciado, no qual as alterações ocorridas haviam sido consideráveis: já tínhamos docentes que haviam sido formados pelo próprio curso, contando-se, assim, com professores formados para serem professores de História, diferentemente da situação anterior, em que bacharéis de outras áreas vieram compor os quadros da FAFI; também tínhamos tido o ingresso de professores formados em outros cursos de História fora de Alagoas, como é o caso de Vera Lúcia Calheiros Mata, formada pela PUC/São Paulo, na década de 1960, que começou a fazer parte dos quadros funcionais do curso ainda na década anterior. A experiência desta, enquanto aluna da PUC/SP, foi fundamental para a presença, no curso, de novos conceitos no campo da História, sobretudo pela vivência e participação como discente no Centro de Estudos Históricos da PUC, uma instituição que tinha o caráter de uma entidade de pesquisa e funcionava em plena colaboração com a Associação Nacional dos Professores Universitários de História (ANPUH).

A vivência como aluna de um centro cultural como São Paulo permitiu que Vera Lúcia Calheiros Mata imprimisse uma marca diferenciada no curso de 
História de Alagoas, inclusive, tratando de referenciais teóricos ausentes da universidade naquele momento, como é o caso do pensador alemão Karl Marx. Infelizmente, essa marca não conseguiu se tornar hegemônica no interior do curso.

Apesar desses novos ventos trazidos ao curso - de fora, claro, como quase tudo o que é novo e que circula em Alagoas -, a marca fundamental dos anos de 1970 será ainda a presença de mais professores padres compondo os quadros docentes do curso, reforçando a marca da Filosofia e da formação humanista dominante, além das reformas universitárias já referidas, que vêm da década de 1960 e que consolidam a estrutura organizacional da UFAL nesta década.

Com a instalação do regime militar em 1964, alterou-se profundamente 0 panorama das Ciências Humanas no Brasil. A censura foi implacável com os cursos de História. Tida como uma disciplina subversiva, a História acabou sendo uma das disciplinas mais afetadas pelas reformas curriculares do regime militar. Isso pode ser traduzido na criação das disciplinas Educação Moral e Cívica e Organização Social e Política do Brasil para a Educação Básica, e Estudo dos Problemas Brasileiros para o ensino universitário, como também pela criação do curso de Estudos Sociais, que, segundo estudiosos do ensino de História, como Selva Guimarães Fonseca, foi uma forma de descaracterizar e esvaziar o ensino de História de seu caráter político ou instrumentalizar os cursos de História para se alinhar à ditadura. Tudo isso vai se refletir, também, no seio da UFAL, na relação com o seu curso de História: aqui, enquanto a criação do curso de Estudos Sociais vai esgarçar ainda mais a pouca densidade existente nos estudos para a formação dos professores de História, a repressão vai tornar praticamente impossível a manifestação mais ampliada daquela postura crítica revelada, num certo momento, pela professora Vera Calheiros, assim como a organização e expressão dos estudantes daquele e dos demais cursos da UFAL. Era um tempo - sob o peso do Decreto 477 - em que a oposição e a crítica, ainda que teóricas e acadêmicas, somente podiam existir de forma clandestina, sob pena de perda da liberdade e, até, da própria vida.

Na UFAL, o alinhamento da reitoria com a ditadura militar permitiu que as medidas fossem implantadas sem maiores entraves. Na Universidade 
Federal de Alagoas, o curso de Estudos Sociais, com habilitação para o ensino de Educação Moral e Cívica - mas cujos diplomados terminavam por ensinar, também, História - foi criado em 1973, fazendo parte do departamento de Estudos Sociais (ESO).

Quanto ao curso de História propriamente dito, que sofria, também, forte influência dessa política de civismo imposta às universidades pela Ditadura, nas entrevistas feitas e na análise dos documentos, é possível perceber, na década de 1970, certo interesse dos docentes por formação continuada, em nível de pós-graduação, o que resultaria na ida de muitos professores para cursos de especialização e mestrado. No entanto, se esse intento não contava, na UFAL, nesse período, com uma política igual à que temos atualmente nessa área, imagine-se o que ocorria na década anterior.

Essa necessidade de mais formação acadêmica por parte dos docentes de História da UFAL acabava, ainda que lentamente, entrando em sintonia com a própria universidade que passava pela euforia da construção do seu campus universitário e começava a direcionar seus esforços na titulação do seu corpo docente, mesmo que caminhando a passos lentos (cf. VERÇOSA, 1997). De qualquer modo, na História, como em algumas outras áreas, o desafio da universidade ainda hoje reside justamente em transformar essa maior titulação em nível de mestrado e doutorado em produção de pesquisa e, o que seria mais desejável, incidente sobre a formação de professores, já que, tal qual a História, muitos cursos com um número bastante significativo de mestres e doutores, mantiveram por décadas, ou ainda mantêm, somente cursos de licenciatura.

Em se tratando do curso de História, pode-se afirmar que a matriz curricular da década de 1970, diversa da existente na fundação do curso, é um dos elementos mais significativos a se examinar, quando pensamos no projeto de formação empreendido, pois é nele que se verificam as grandes possibilidades de mudanças conceituais do curso. De fato, a matriz curricular desse período, por mim classificado como de consolidação do curso, é um forte indício de que a formação do professor de História no seio da UFAL parecia estar caminhando para uma alteração considerável do ponto de vista teóricoepistemológico. Embora ela mantivesse o modelo quadripartite de herança francesa (História Antiga, Medieval, Moderna e Contemporânea) que primava 
por uma visão eurocêntrica de História, várias disciplinas, que vão surgir como optativas, sinalizavam outro momento do curso, justamente quando, não tendo mais como retroceder, o curso pode ser dado como consolidado, formatando de um modo bem preciso a formação do professor de História na Universidade Federal de Alagoas.

Entre as disciplinas obrigatórias da matriz curricular do ciclo básico da década de 1970 constavam: Introdução às Ciências Sociais, Introdução à Metodologia Científica, Estudos dos Problemas Brasileiros I, Estudos dos Problemas Brasileiros II, Educação Física, Introdução à Filosofia e Introdução ao Estudo da História I. Entre as optativas constavam: Língua Francesa I, Língua Inglesa I, Língua Portuguesa I e Introdução à Psicologia.

Nesse ciclo básico observa-se, claramente, como as disciplinas são direcionadas para a formação cívica preconizada pela reforma universitária. 0 ciclo básico optativo revela ainda uma forte tendência na formação instrumental. De qualquer sorte, há aqui um perfil mais moderno e ampliado, quando comparado com o projeto de curso delineado na sua criação, com disciplinas como Metodologia Científica e Introdução às Ciências Sociais.

Já no ciclo profissional, as disciplinas se organizam em três níveis: disciplinas obrigatórias, disciplinas semi-optativas e disciplinas optativas. As disciplinas obrigatórias eram: Introdução ao Estudo da História I, Introdução ao Estudo da História II, Geo-História, Antropologia Cultural, História da América Pré-colombiana, História Antiga, História Medieval, História Moderna, História Contemporânea, História do Brasil I, História do Brasil II, História do Brasil III, História da América, Didática, Didática II, Psicologia da Educação I, Psicologia da Educação II, Psicologia da Educação III, Estrutura e Funcionamento do Ensino de $1^{\circ}$ grau, Estrutura e Funcionamento do Ensino de $2^{\circ}$ grau e Prática de Ensino - Estágio de História. Entre o grupo das disciplinas semi-optativas, das quais o aluno devia escolher duas disciplinas ou mais, constavam: História das Idéias Políticas e Sociais, Teoria Sociológica, Civilização Ibérica, História Econômica, História da Arte I, Literatura Brasileira I, Noções de História da Filosofia, Filosofia da Cultura, Disciplinas Auxiliares da História, Organização Social e Política do Brasil, História de Alagoas I e História de Alagoas II. Faziam parte, por sua vez, do grupo das disciplinas optativas: Folclore I, Folclore II, Arqueologia, Arqueologia do Brasil, Teoria Sociológica II, História do 
Nordeste, História da Cultura Alagoana, Cultura Greco-Romana, Filosofia da História, História da Religião, História das Culturas, Análise de textos históricos, Atualidades históricas, Técnicas de pesquisa histórica, Atualidades históricas brasileiras, História da Arte II, Antropologia do Brasil I e Antropologia do Brasil II.

Se compararmos os quadros acima, considerando a natureza das disciplinas na matriz curricular com a matriz da fundação, é possível perceber que, entre as disciplinas obrigatórias do ciclo profissional fica evidenciada a herança da primeira matriz, o que nos leva a concluir que as mudanças ocorridas no núcleo do projeto pedagógico do curso se deram de forma marginal, no sentido de que as inovações trazidas do ponto de vista teórico e metodológico, que vão aparecer no rol das disciplinas semi-optativas e optativas, não iriam fazer parte da formação básica de todos os discentes, mas apenas daqueles que, por um motivo ou outro, decidissem fazer determinadas disciplinas ofertadas. De qualquer modo, são marcantes do novo entre as semioptativas e optativas, as disciplinas: História de Alagoas I, História de Alagoas II, História do Nordeste e História da Cultura Alagoana. A criação destas disciplinas nos leva a crer na evidência de certa preocupação com a problemática local que infelizmente não estava presente quando da fundação do curso, mas que, segundo testemunhos de ex-alunos entrevistados, era uma cobrança constante, sobretudo do movimento estudantil, quando consideravam a missão da universidade.

Já no tocante às discussões teóricas e metodológicas no campo da Teoria da História podemos salientar a importância que teve a criação das disciplinas Análise de Textos Históricos, Filosofia da História e Técnicas de Pesquisa Histórica. Essa três disciplinas parecem evidenciar uma possível preocupação com a discussão sobre a natureza do saber histórico, problematizando sua construção e reconstrução. Contudo, onde estavam localizados esses saberes na matriz curricular nos anos de 1970? Na periferia do projeto formativo, uma vez que se encontravam, também, entre as optativas.

Em se tratando da pesquisa histórica em arquivos, é forçoso assinalar que os vínculos do curso com o Arquivo Público eram mais estreitos do que são atualmente, influindo, com certeza, na criação da disciplina História de Alagoas, que foi ministrada desde sua institucionalização curricular pelo 
professor Moacir Medeiros de Sant'Ana, fundador e diretor daquela instituição por décadas.

Embora, na década de 1970, o curso de História, ao menos no seu desenho curricular, não fosse mais um bacharelado clássico, ao qual se acoplava uma formação docente, e sim um curso de licenciatura no sentido formal, e ainda que pareça haver nessa matriz curricular uma preocupação considerável com a pesquisa histórica, o que me causou admiração enquanto aluna que fui do curso e me surpreendeu, sobremaneira, quando da realização das entrevistas, é que esses intentos parecem não ter se concretizado. Não é possível negar que, naquele período, a considerar os depoimentos por mim colhidos, houvesse pesquisa histórica, realizada por alunos em instituições de pesquisa como o Arquivo Público e o Instituto Histórico; no entanto, ela ocorria de maneira difusa e por iniciativa isolada de docentes, não correspondendo a uma prática institucionalizada que pudesse deixar marcas mais profundas nos formandos e em sua prática docente.

Enquanto isso, a criação de disciplinas que discutiam cultura, como Antropologia Cultural, História das Idéias Políticas e Sociais, Civilização Ibérica, História da Arte I e II, Literatura Brasileira I, Filosofia da Cultura, Folclore I e II, Arqueologia, Arqueologia do Brasil, História da Cultura Alagoana, Cultura Greco-Romana, História da Religião, História das Culturas, Antropologia do Brasil I e II, pareciam demonstrar uma preocupação de pensar a História de forma interdisciplinar.

Feito um balanço do que ocorreu no curso nos anos de 1970, é possível perceber que todas essas alterações então ocorridas certamente vieram compor um quadro mais complexo do que o visto anteriormente. Embora a formação não direcionasse o profissional de forma mais sistemática para a pesquisa histórica propriamente dita, nem refletisse de forma mais minuciosa a importância da formação de um professor de História, salvo honrosas exceções no curso, havia, sim, a possibilidade da formação de um historiador erudito, perfeitamente coerente com a necessidade da formação de um professor na sociedade alagoana da época. No entanto, a matriz epistemológica dominante no interior do curso parece ter inviabilizado essa perspectiva de abertura teórico-metodológica que aparentemente se esboça na matriz curricular dos anos de 1970 e que, num certo sentido, foi reforçada pela conjuntura autoritária 
em que se vivia. Penso ser possível afirmar que a década de 1970 se encerra para o curso de História da UFAL apontando um panorama onde a formação humanistíco-ilustrada era o viés dominante que conduzia a formação do futuro professor de História, o qual ainda não visualizava a pesquisa como algo fundamental na formação, tendo na trasnsmissão do conteúdo o eixo norteador da docência e na história dos eventos, como diria Marc Bloch, sua tônica. Quanto à aparente vitalidade do curso na época, somente um estudo de sua trajetória ao longo das décadas de 1980 e 1990, é que poderá explicitar, pelos seus frutos, se havia apenas um clima tendente à inovação ou se, nos limites estreitos da ditadura em que o curso ocorria, vivia-se simplesmente a continuidade de uma rotina que se mostrava inovadora apenas no plano da matriz curricular.

A despeito de tudo o que foi produzido no campo da História ocidental, sobretudo na primeira metade do Século XX, no tocante à revolução teóricometodológica que mudou, inclusive, a configuração da disciplina, tanto na Europa, quanto na academia brasileira, Alagoas, mesmo tendo, desde o início dos anos de 1950, uma instituição de educação superior que formava profissionais da História, passou ao largo dessa revolução, dialogando com as inovações teórico-metodológicas de maneira marginal, sem fazer ressoar, de fato, uma outra formação, tendo o novo, no campo da História, quando produzido, sendo feito regularmente por intelectuais não historiadores, estando nesse meio um ou outro profissional originariamente formado no campo.

\section{Referências Bibliográficas:}

1. ALBERTI, Verena. Fontes Orais: Histórias dentro da História. In: PINSKY, Carla Bassanezi. Fontes Históricas. São Paulo: Contexto, 2005.

2. ALMEIDA, Luiz Sávio de (org.) Dois textos alagoanos exemplares. Maceió: FUNESA, 2004.

3. $\mathrm{BLOCH}$, Marc Leopold Benjamin. Apologia da história ou o ofício do historiador. Rio de Janeiro: Jorge Zahar, 2001.

4. BURKE, Peter. A Escola dos Annales (1929-1989): a revolução francesa da historiografia. São Paulo: Fundação Editora UNESP, 1997. 
5. FAVERO, Maria de Lourdes. Universidade do Brasil: das origens à construção. $1^{\circ}$ ed. Rio de Janeiro: Editora UFRJ/INEP, 2000, volume 1.

6. Universidade do Brasil: Guia dos Dispositivos Legais. Rio de Janeiro: Editora UFRJ/INEP, 2000.

7. ___ (coord.) FACULDADE NACIONAL DE FILOSOFIA: projeto ou trama universitária. Rio de Janeiro: Editora UFRJ, 1989. Volume 1.

8. (coord.) FACULDADE NACIONAL DE FILOSOFIA: o corpo docente, matizes de uma proposta autoritária. Rio de Janeiro: Editora UFRJ, 1989. Volume 2.

9. (coord.) FACULDADE NACIONAL DE FILOSOFIA: caminhos e descaminhos. Rio de Janeiro: Editora UFRJ, 1989. Volume 3.

10. (coord.) FACULDADE NACIONAL DE FILOSOFIA: os cursos começando a desenrolar seu novelo. Rio de Janeiro: Editora UFRJ, 1989. Volume 4.

11. (coord.) FACULDADE NACIONAL DE FILOSOFIA: depoimentos. Rio de Janeiro: Editora UFRJ, 1992. Volume5.

12. FONSECA, Selva Guimarães. Caminhos da História ensinada. $3^{\circ}$ ed. Campinas: Papirus, 1995.

13. FONSECA, Thais Nívia de Lima e. História e ensino de História. $2^{0}$ ed. Belo Horizonte: Autêntica, 2004.

14. FURET, François. A Oficina da História. Lisboa: Gradiva, s.d.

15. GUIMARÃES, Manoel Luís Salgado. Nação e Civilização nos Trópicos: O Instituto Histórico e Geográfico Brasileiro e o Projeto de uma História Nacional. In: Revista de Estudos Históricos do CPDOC/FGV, Rio de Janeiro, n. 1, 1988. pp. 5-27.

16. KARNAL, Leandro (org.) História na sala de aula: conceitos, práticas e propostas. São Paulo: Contexto, 2003.

17. NEVES, Joana. A formação do professor de História no Brasil. In: SCOCUGLIA, Afonso Celso (org.). Educação e História no Brasil contemporâneo. João Pessoa: Editora Universitária UFPB, 2003.

18. REIS, José Carlos. Escola dos Annales: A inovação em História. $2^{\circ}$ ed. São Paulo: Paz e Terra, 2000.

19.

A História: entre a filosofia e a ciência. $2^{\circ}$ ed. São Paulo: Ática, 1999. 
20. ROCHA, José Maria Tenório. Revista do Instituto Histórico e Geográfico de Alagoas: Bibliografia analítica. Maceió: Gráfica e Editora Triunfo Ltda, 1999.

21. SAMARA, Eni de Mesquita e TUPY, Ismênia Spínola Silveira Truzzi. História \& Documento e metodologia de pesquisa. Belo Horizonte: Autêntica, 2007.

22. SCHWARCZ, Lilia Moritz. O espetáculo das raças: cientistas, instituições e questão racial no Brasil 1870-1930. São Paulo: Companhia das Letras, 1993.

23. TAVARES, Maria das Graças Medeiros \& VERÇOSA, Elcio de Gusmão. UFAL- de um fenômeno tardio a uma maturidade singular. In: MOROSINI, Marília (org.). A Universidade no Brasil: concepções e modelos. Brasília: INEP, 2006.

24. Educação superior pública em Alagoas - 10 anos pósLDBEN: da predominância da ação profissionalizante ao alargamento das condições de produção e socialização do conhecimento. In: BITTAR, Mariluce (org.). Educação Superior no Brasil: 10 anos pósLDB. Brasília: INEP, 2008.

25. TENÓRIO, Douglas Apratto \& DANTAS, Carmem Lúcia. A Casa das Alagoas: Instituto Histórico e Geográfico de Alagoas. Maceió: EDUFAL, 2007A.

26. TENÓRIO, Douglas Apratto. A Tragédia do Populismo. $2^{\circ}$ ed. Maceió: EDUFAL, 2007B.

27. VERÇOSA, Elcio de Gusmão. Burocracia e Oligarquia: um estudo de caso sobre o poder universitário. Tese de doutorado apresentada ao Programa de Pós-Graduação em História e Filosofia da Educação da Universidade de São Paulo, 1996.

28._História do ensino superior em Alagoas: verso e reverso. Maceió: EDUFAL, 1997.

29.

A propósito dos textos didáticos na prática escolar: uma abordagem sociopolítica da ação docente. Maceió: Edições Catavento, 1999.

30.__ Cultura e Educação nas Alagoas: história, histórias. 4ํe. ed. Maceió: EDUFAL, 2006. 
